\title{
Approximate recovery of coseismic deformation from Taiwan strong-motion records
}

\author{
Yih-Min Wu • Chien-Fu Wu
}

Received: 11 April 2006 / Accepted: 15 December 2006 / Published online: 16 January 2007

(C) Springer Science + Business Media B.V. 2007

\begin{abstract}
Since 1990, digital strong-motion accelerographs and global positioning system (GPS) instruments have been widely deployed in the Taiwan region (Shin et al. 2003; Yu et al. 2001). The 1999 Chi-Chi, Mw 7.6 earthquake and the 2003 Chengkung, Mw 6.8 earthquake were well recorded by both digital accelerographs and GPS instruments. These data offer a good opportunity to determine coseismic displacements from strong-motion records and to compare the results with those derived from GPS measurements. As noted by Boore (2001), a double integration of the acceleration data often leads to unreasonable results, and baseline corrections are therefore required in most cases before the integration. Based on the works of Iwan et al. (1985) and Boore (2001), we developed an improved method for baseline correction and validated it using an extensive set of data from shake-table tests of a known "step" displacement on 249 accelerographs. Our baseline correction method recovered about $97 \%$ of the actual displacement from the shaketable data. We then applied this baseline correction method to compute coseismic displacements from the
\end{abstract}

Y.-M. Wu $(\bowtie)$

Department of Geosciences, National Taiwan University,

No. 1, Sec. 4th, Roosevelt Rd.,

Taipei, Taiwan, Republic of China

e-mail: drymwu@ntu.edu.tw

C.-F. Wu

Central Weather Bureau,

Taipei, Taiwan, Republic of China strong-motion data of the Chi-Chi and Chengkung earthquakes. Our results agree favorably with the coseismic displacements determined by the GPS measurements at nearby sites. The ratio of seismic to geodetic displacement varies from 0.78 to 1.41 , with an average of about 1.05 .

Key words strong-motion record · GPS

coseismic deformation $\cdot$ baseline correction

\section{Introduction}

In 1991, the Central Weather Bureau (CWB) of Taiwan undertook a 6-year Taiwan Strong-Motion Instrumentation Program (TSMIP) to deploy over 600 digital accelerographs on free-field sites and an equivalent number of accelerographs in buildings and on bridges (Shin et al. 2003). With a station spacing of a few kilometers (except in unpopulated high-mountain areas), all felt earthquakes in Taiwan have been well recorded by the TSMIP network. In particular, the 1999 Chi-Chi earthquake $(\mathrm{Mw}=7.6)$ in central Taiwan was the best-recorded major earthquake in the 20th century, and the data were quickly released by the CWB (Lee et al. 1999, 2001).

The frequency response of a digital accelerograph is nominally flat in translational acceleration from DC to about $50 \mathrm{~Hz}$. If there is no coseismic deformation at the accelerograph site and if the background and instrumental noises are low, the time histories of 
velocity and displacement during an earthquake can be recovered from the integrations of the acceleration data (with a DC correction by removing the mean determined from the pre-event segment of the record). However, if coseismic deformation occurs at the accelerograph site, an appropriate baseline correction is needed; otherwise, unreasonable displacements may result (Boore 2001; Boore et al. 2002). On the other hand, if six components of strong motion (three translational and three rotational) are recorded (Graizer 1989, 2005; Niggbor 1994; Trifunac and Todorovska 2001), the coseismic deformation can be precisely calculated. Currently, most of the strong-motion instruments are only the three translational components. Thus, anempirical and approximate approach must be considered.

Discussions on how coseismic deformation can be recovered from strong-motion record have been published since 1976 (Bogdanov and Graizer 1976; Graizer 1979, 1989). Methods of baseline correction to digital strong-motion records have been proposed later, for example, by Iwan et al. (1985) and Chiu (1997). In Chiu's method, the strong-motion data are first high-pass-filtered before integration. Thus, it can recover some but not all of the permanent displacement occurred, and his method is more appropriate for earthquake engineering purposes. The method of Iwan et al. (1985) appears to recover the permanent displacement, but the time points of the baseline corrections in Iwan et al. (1985) may not be where they are assumed to be, as pointed out by Boore (2001). In particular, Boore (2001) showed that various reasonable baseline correction schemes can lead to wildly different final displacements using the strong-motion records from the 1999 Chi-Chi earthquake.

The strong-motion records of the 1999 Chi-Chi main shock $(\mathrm{Mw}=7.6)$ have been used to estimate coseismic deformation by many authors (e.g., Boore 2001; Chung and Shin 1999), suggesting a coseismic deformation of up to about $7 \mathrm{~m}$. However, there is not a standard procedure for baseline correction in processing strong-motion records in general. In this paper, we develop an improved method for baseline correction and validate it using an extensive set of data from shake-table tests of a known "step" displacement on 249 accelerographs. We then apply this baseline correction method to compute coseismic deformation from the strong-motion data of the 1999 Chi-Chi and 2003 Chengkung earthquakes.

\section{An improved method for baseline correction}

Iwan et al. (1985) attributed the source of the baseline shift to a hysteresis in the transducer that occurs when acceleration exceeds about $50 \mathrm{~cm} / \mathrm{s}^{2}$. Consequently, the baseline shift could change in a complicated way during the strongest shaking interval, and the baseline offset after the strong shaking
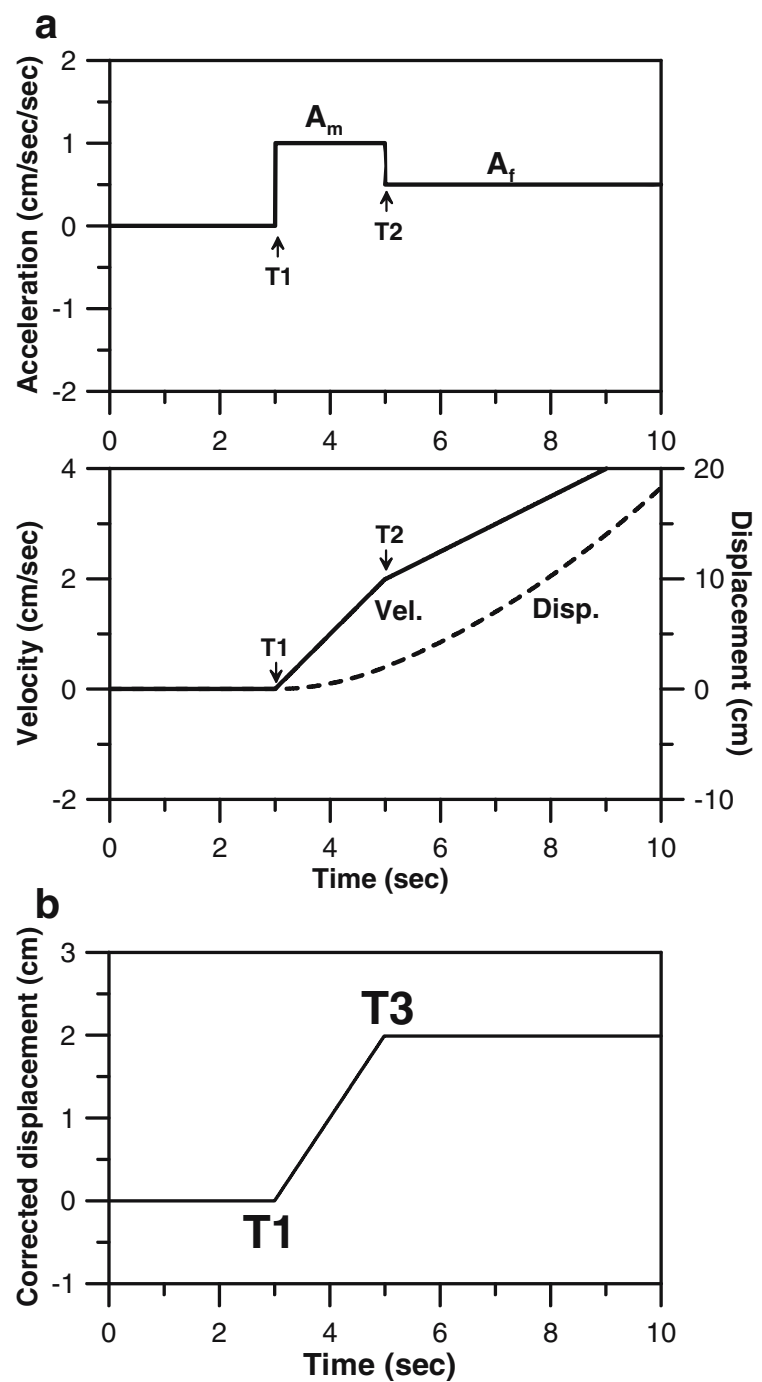

Fig. 1 (a) Iwan et al. (1985) baseline correction scheme from acceleration (top) to velocity and displacement (bottom). (b) A "good" corrected displacement history is similar to the ramp function. We propose to choose $\mathrm{T} 1$ the point at which the ground starts to move to the permanent displacement position, and $\mathrm{T} 3$ the point when the ground has just moved to the permanent displacement position 
Fig. 2 Top: Observed acceleration for the east-west component at station TTN014 from December 10, 2003 (Mw6.8) earthquake. Middle: Velocities integrated from uncorrected (red) and corrected (black) accelerations. Bottom: Displacements for the uncorrected (red) and corrected (black) cases. After baseline corrections and double integration, $9.4 \mathrm{~cm}$ of permanent eastward displacement was obtained. At an almost co-site GPS station, a 9.3$\mathrm{cm}$ eastward displacement was observed. Vertical lines mark T1, T2, and T3 show the correction time points. The thick red line plotted in the velocity record shows the correction baseline

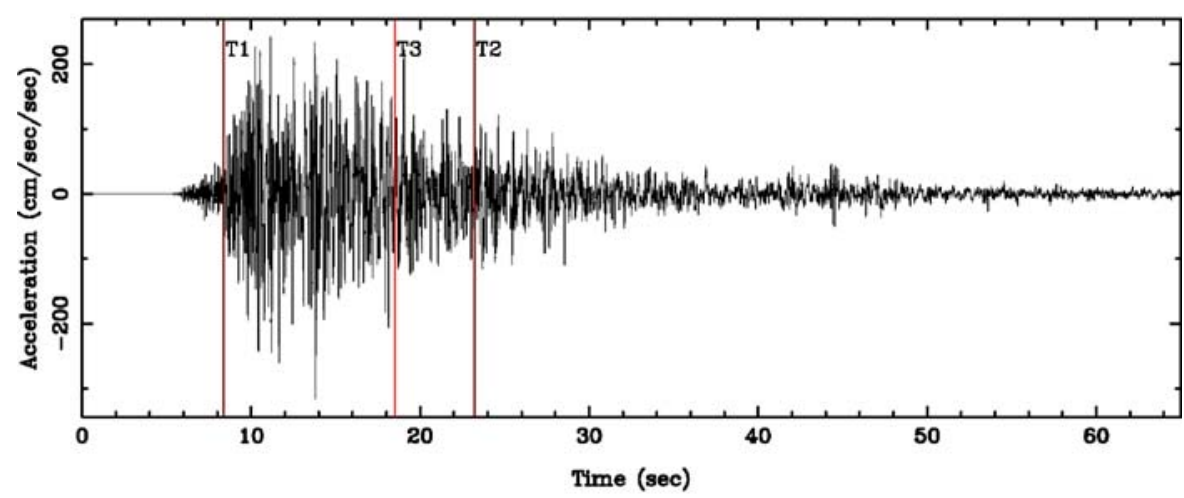

TTN014 Corrected and Raw Data, Fllename $=$ T411002.344, N-S Component

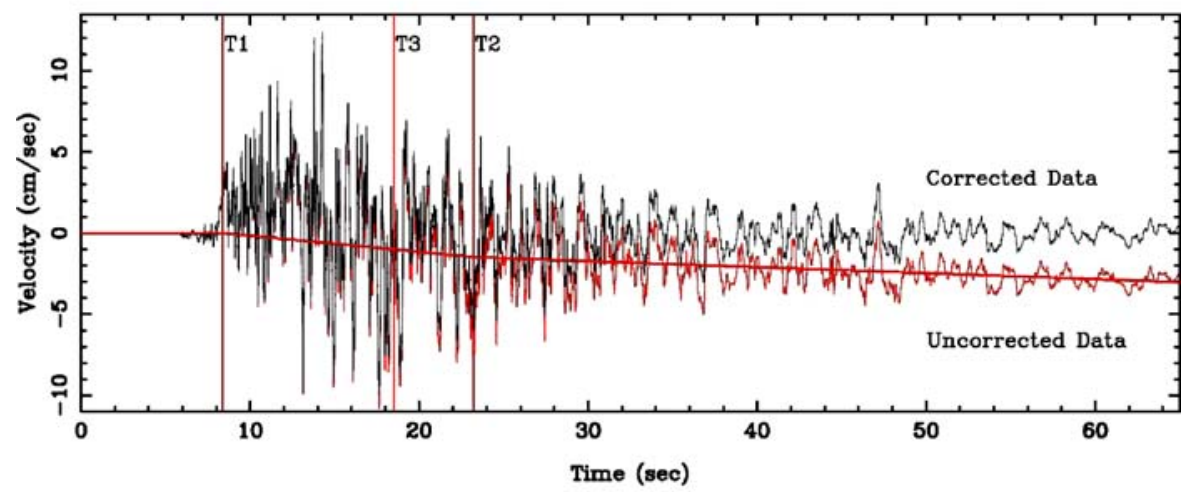

TTN014 Corrected and Raw Data, Filename=T411002.344, N-S Component

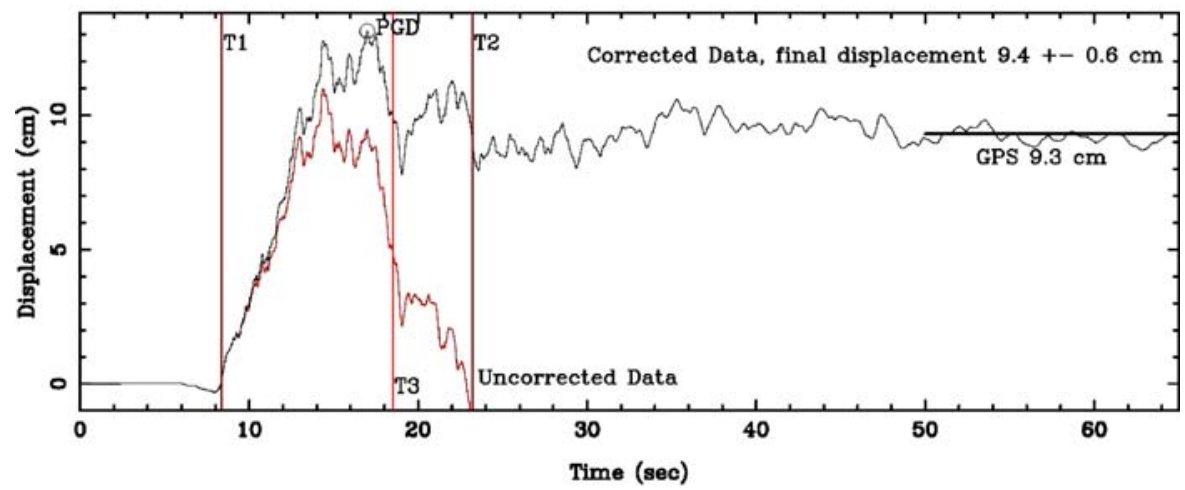

may be different from that before the strong shaking. Iwan et al. (1985) then proposed that two baseline offsets be removed: $A_{\mathrm{m}}$ between times $\mathrm{T} 1$ and $\mathrm{T} 2$, where $\mathrm{T} 1$ and $\mathrm{T} 2$ are the start and end times of the strongest shaking interval, respectively, and $A_{\mathrm{f}}$ from time $\mathrm{T} 2$ to the end of the record (Fig. 1a). The value $A_{\mathrm{m}}$ is an average of the complicated shifts in baseline that occur during the strong shaking. The level $A_{\mathrm{f}}$ is determined from the slope of a linear fit to a portion of the velocity trace following the strong shaking:

$\mathrm{V}_{\mathrm{f}}(\mathrm{t})=\mathrm{V}_{0}+\mathrm{A}_{\mathrm{f}} \mathrm{t}$

In practice, the $V_{\mathrm{f}}$ line is found by a least-squares fit of the portion of the velocity from $\mathrm{T} 2$ to end of the 
record. The correction $A_{\mathrm{m}}$ can be determined (Boore 2001) by

$A_{m}=\frac{V_{f}(T 2)}{(T 2-T 1)}$

Boore (2001) suggested that hysteresis may be just one of the reasons causing baseline offsets, and that tilting of the ground must also be considered. We note that many of the velocities derived from uncorrected acceleration records from Taiwan show an approximately linear trend at long times. These records were taken either in near sources regions of large earthquakes (Chung and Shin 1999; Wu et al. 2006a, b) or very close to the epicenters of smaller earthquakes that may have localized coseismic deformations. Boore et al. (2002) further pointed out that there may be numerous other sources of offsets (e.g., hysteresis in the sensor, static buildup in the $\mathrm{A} / \mathrm{D}$ converter, or tilting of the ground).

Based on the strong-motion records from TSMIP station and laboratory tests, we also obtained the baseline offset in Fig. 1a. This suggests that the method of Iwan et al. (1985) can provide a useful approximation, but that it is necessary to clearly define the $\mathrm{T} 1$ and $\mathrm{T} 2$ time points, as pointed out in Boore (2001). Iwan et al. (1985) chose T1 as the time that the absolute value of acceleration first exceeds $50 \mathrm{~cm} / \mathrm{s}^{2}$, and proposed two specific options for T2: (1) the time after which the acceleration never exceeds $50 \mathrm{~cm} / \mathrm{s}^{2}$; and (2) the value that minimizes the final displacement. However, using the correction of Iwan et al. (1985) does not lead to satisfactory results for the 1999 Chi-Chi earthquake, as noted in Boore (2001). Consequently, Boore (2001) suggested that $\mathrm{T} 1$ be made a free parameter and not determined by a threshold of shaking, and that $\mathrm{T} 2$ can take any value between $\mathrm{T} 1$ and the end of the record so long as the average corrected velocity is zero near the end of the record. However, with T1 being a free parameter, a wide range of final displacements may be obtained.

Generally, T1 should be chosen to be the point in the record where the ground starts to move from zero displacement. However, such a point is not always clear on the records, and it is also not necessarily the time at which the acceleration exceeds $50 \mathrm{~cm} / \mathrm{s}^{2}$.

Based on the results of Boore (2001) and our experience in processing strong-motion data with coseismic deformation (Wu et al. 2006a,b), we found that the corrected displacement history takes the shape of a ramp function (Fig. 1b). We therefore propose that $\mathrm{T} 1$ should be chosen to be the time at which the ground starts to move from zero displacement. If the $\mathrm{T} 1$ so determined is earlier than the time at which the absolute value of the acceleration first exceeds $50 \mathrm{~cm} / \mathrm{s}^{2}$ (i.e. T1 in Iwan et al. 1985), then we will select Iwan et al.'s T1 point.

After the ground moves to the permanent displacement position, the corrected displacement history should be very flat (Wu et al. 2006a,b). Thus, we define a correction time point $\mathrm{T} 3$ at which the ground has just moved to the permanent displacement position (Fig. 1b), and an $f$-value was determined using the waveform from $\mathrm{T} 3$ to the end of the record.

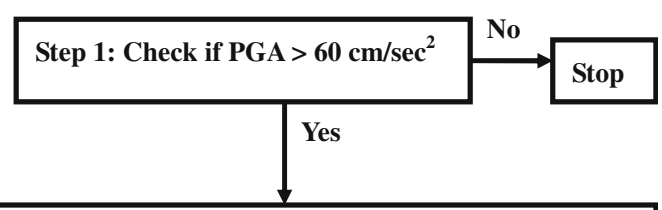

Step 2: Raw data integrated to velocity and displacement records. Plot acceleration, velocity, and displacement time histograms and choose $\mathrm{T} 1$ and $\mathrm{T} 3$ time points.

Step 3: Make baseline correction in velocity record and determine f-value in corrected displacement record by taking as $\mathrm{T} 2$ every time point from $\mathrm{T} 3$ to the end of the record. Selecting the time point with a maximum f-value as the final $\mathbf{T} 2$.

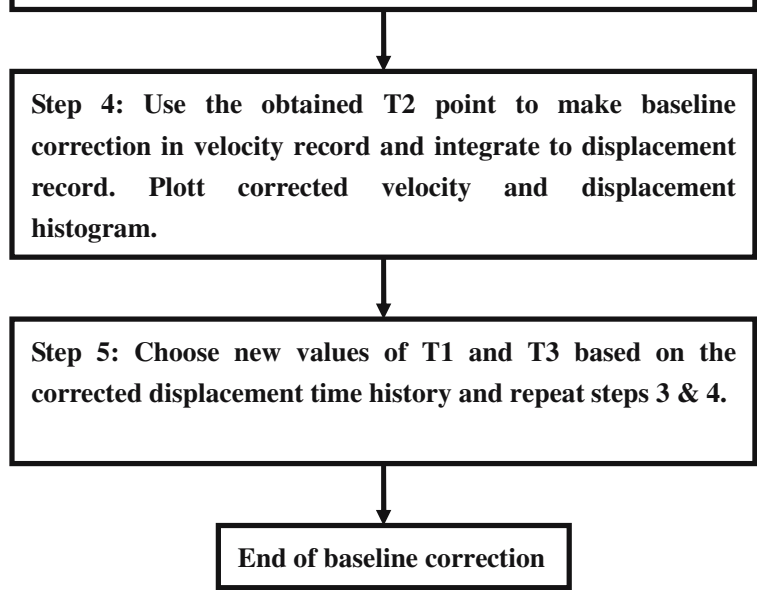

Fig. 3 Flow chart showing our baseline correction procedures 
The $f$-value is a "flatness" indicator obtained from the corrected displacement history and is defined as

$f=\frac{|r|}{|b| \cdot \sigma}$

where $r$ is the linear correlation coefficient and $b$ is the slope of the least-squares regression line of the corrected displacement history from T3 to the end of the record. We regard the mean value of the corrected displacement history from $\mathrm{T} 3$ to the end of the record as the "permanent displacement" and determine its variance $\sigma$. For a "good" strong-motion record, the displacement history should be very flat after T3. Thus, the absolute value of $r$ should be very close to $1, b$ should be close to 0 , and $\sigma$ is at a minimum value. Under this condition, the $f$-value reaches to a maximum.
Fig. 4 Top: Observed acceleration for the northsouth component of an A900 accelerograph (serial number 076) from a shaketable "step" test. Middle: Velocities integrated from uncorrected (red) and corrected (black) accelerations. Bottom: Displacements for the uncorrected (red) and uncorrected (black) cases. After baseline corrections and double integration, about $0.3-\mathrm{cm}$ permanent displacement was obtained. Vertical lines marked by T1, $\mathrm{T} 2$, and $\mathrm{T} 3$ indicate the correction time points

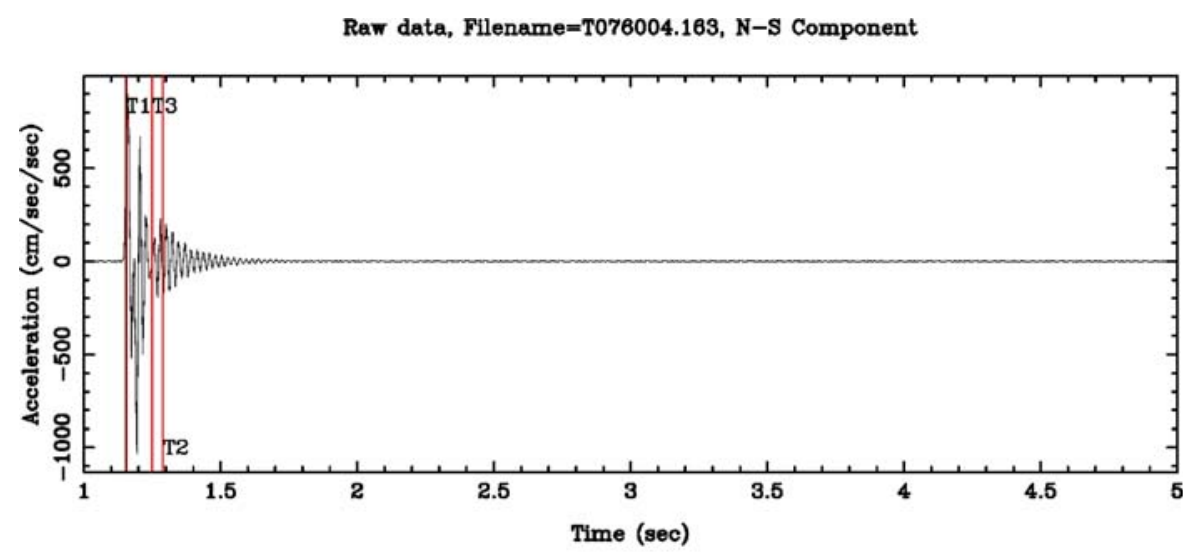

Corrected and Raw Data, Filename=T076004.163, N-S Component

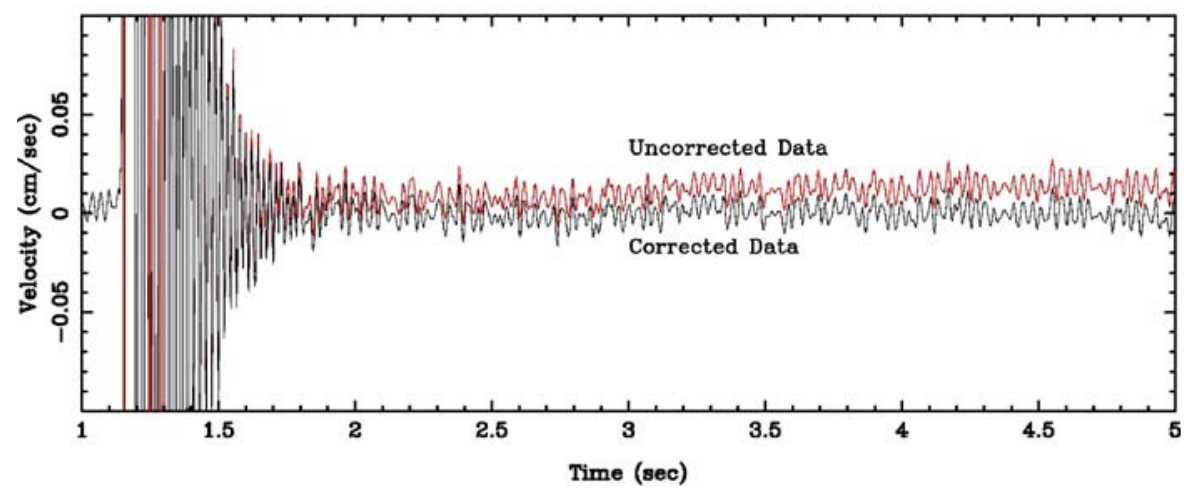

Corrected and Raw Data, Filename=T076004.183, N-S Component

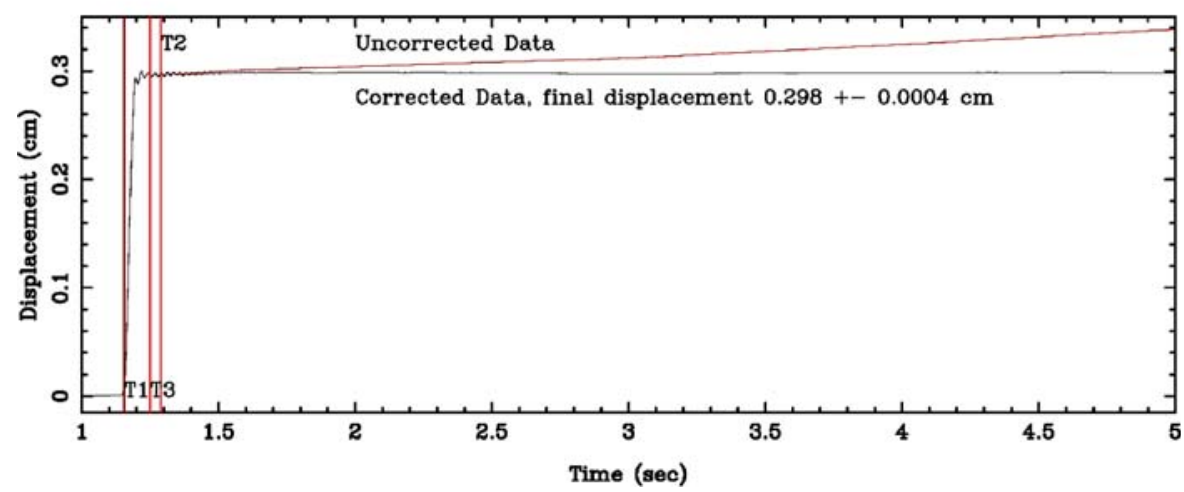


For T2, we defined it to be the value between T3 and the end of the record such that the $f$-value determined from the corrected displacement history is a maximum. We conduct baseline correction to the velocity record as mentioned above by taking as tentative $\mathrm{T} 2$ every time point from $\mathrm{T} 3$ to the end of the record. Then, we select the time point that gives the maximum $f$-value as the final $\mathrm{T} 2$. We use a leastsquares fit to the portion of the velocity record from $\mathrm{T} 2$ to end of the record to determine the $V_{\mathrm{f}}$ line and the $A_{\mathrm{m}}$ value.

Figure 2 shows the corrected and raw data of a strong-motion record. Vertical lines marked by T1, $\mathrm{T} 2$, and T3 show the time points for baseline corrections. Because the $\mathrm{T} 1$ and $\mathrm{T} 3$ points are estimated by inspecting the integration results, two or more steps in baseline corrections are necessary in our method. Figure 3 is a schematic diagram of our procedures.

\section{Data from shake-table tests}

Most of the TSMIP instruments have been subjected to shake-table tests before installation in the field (CWB Instrumentation Committee 1994). The most important test is by using a series of "steps" (square waves with slightly rounded corners) as the input signal to the shake table. Displacements of $0.3-\mathrm{cm}$ "steps" are generated on the shake table and recorded by the accelerograph. An accelerograph passes this test if the displacement obtained from double integration of the recorded acceleration is within $\pm 10 \%$ of $0.3 \mathrm{~cm}$. We collected 249 strong-motion records of the shake-table tests conducted about 10 years ago. The tested strong-motion instruments were the Teledyne Geotech Model A900 accelerograph with \pm 2 g full-scale, a 16-bit resolution, and a sampling rate of 200 samples per second. Most of those instruments are still in operation today, and they provided the majority of the strong-motion records of the 1999 Chi-Chi earthquake.

We applied our baseline correction method to this extensive dataset of shake-table "step" test. Figure 4 displays the corrected and uncorrected data recorded by an A900 instrument (serial number 076). This instrument is installed at the TSMIP station TCU068. It recorded the Chi-Chi main shock at a distance of $380 \mathrm{~m}$ from the fault surface rupture, where a peak ground displacement of about $10 \mathrm{~m}$ was observed (Boore 2001; Chung and Shin 1999).

Figure 4 shows that the shake-table test produced a peak amplitude of about $1 \mathrm{~g}$. The record has a very small offset in acceleration, and a linear trend can be seen in the integrated velocity history. After a double integration using our baseline correction method, we obtained a displacement of $0.298 \mathrm{~cm}$, in good agreement with the input of $0.3-\mathrm{cm}$ "step" to the shake table.

Figure 5a shows the results of the 249 accelerographs (Model A900) under the "step" tests, yielding a mean displacement of $0.300 \mathrm{~cm}$ with a standard deviation of $0.009 \mathrm{~cm}$. Figure $5 \mathrm{~b}$ shows the acceleration offset after the $0.3-\mathrm{cm}$ displacement shaking. Most of the instruments caused only very small offsets with a mean acceleration of $-0.002 \mathrm{~cm} / \mathrm{s}^{2}$ and a standard deviation of $0.027 \mathrm{~cm} / \mathrm{s}^{2}$. Generally, the offsets are less than one digital count (one count= $0.0598 \mathrm{~cm} / \mathrm{s}^{2}$ ). Hence, the A900 accelerographs can record the displacement in shake-table tests.
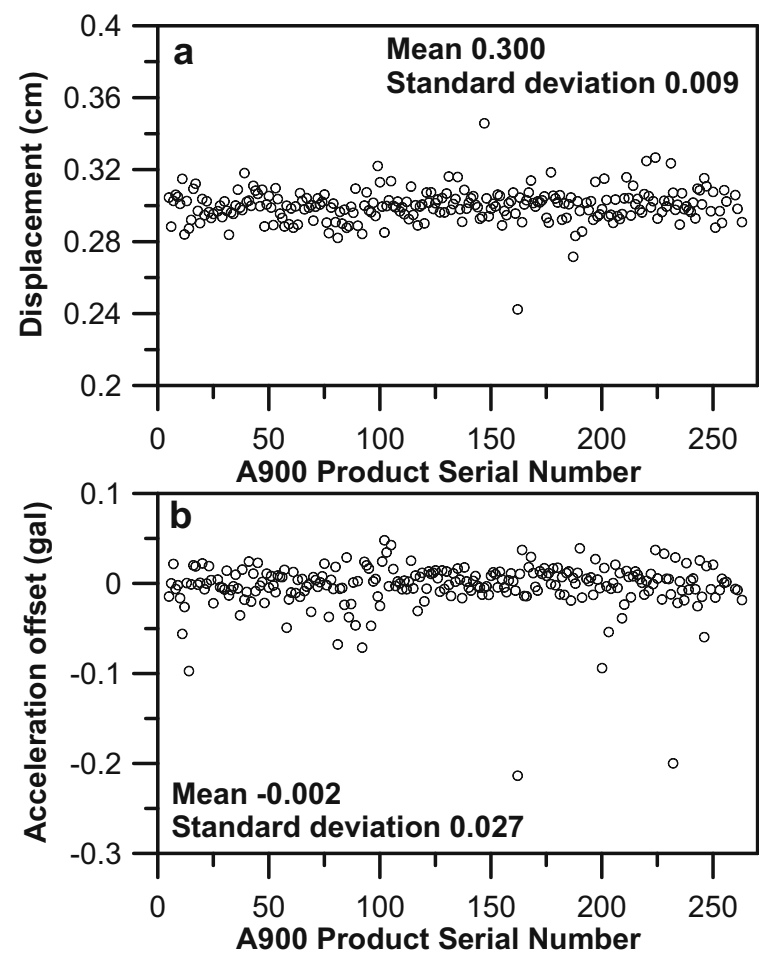

Fig. 5 (a) Permanent displacements obtained by 249 accelerographs from shake-table "step" tests plotted with their serial numbers. (b) Acceleration offsets after a $0.3-\mathrm{cm}$ "step" shaking plotted with their serial numbers (most of the instrument offsets are less than one count) 


\section{Comparing displacements from strong-motion records with nearby GPS observations}

Global positioning system (GPS) observations of coseismic deformations have been reported for the 1999 Chi-Chi, Mw 7.6 earthquake (Yu et al. 2001) and the 2003 Chengkung, Mw 6.8 earthquake (Chen et al.
2006). These two events were well recorded by the TSMIP instruments. Thus, they offer a good opportunity to examine the performance of our baseline correction method in recovering coseismic deformation.

We selected 16 strong-motion records (Table 1) for analysis. The selection criterion is based on data availability: distance between the strong-motion

Table 1 Comparison of coseismic deformation determined from strong-motion data with GPS measurements at 16 stations

\begin{tabular}{|c|c|c|c|c|c|c|c|c|c|c|}
\hline \multicolumn{4}{|l|}{ Strong motion observation } & \multicolumn{5}{|l|}{ GPS } & \multirow{2}{*}{$\begin{array}{l}\text { Distance } \\
(\mathrm{m})\end{array}$} & \multirow{2}{*}{ Event } \\
\hline $\begin{array}{l}\text { Code; filename; } \\
\text { location }\end{array}$ & \multicolumn{3}{|c|}{$\begin{array}{l}\text { Displacement }(\mathrm{cm}) \text {; } \\
\text { vertical-northeast }\end{array}$} & Code; location & \multicolumn{3}{|c|}{$\begin{array}{l}\text { Displacement }(\mathrm{cm}) \text {, } \\
\text { vertical-northeast }\end{array}$} & $\begin{array}{l}\text { Data } \\
\text { source }\end{array}$ & & \\
\hline $\begin{array}{l}\text { TTN014; T411002.344; } \\
23.099^{\circ} \mathrm{N}, 121.365^{\circ} \mathrm{E}\end{array}$ & 12.3 & 9.4 & 6.6 & $\begin{array}{l}\text { CHEN; } \\
23.099^{\circ} \mathrm{N}, \\
121.365^{\circ} \mathrm{E}\end{array}$ & 15.4 & 9.3 & 8.5 & A & 40 & $\begin{array}{c}2003 / 12 / 10 \\
\text { Mw } 6.8\end{array}$ \\
\hline $\begin{array}{l}\text { TTN051; T301001.344; } \\
23.187^{\circ} \mathrm{N}, 121.017^{\circ} \mathrm{E}\end{array}$ & a & -1.8 & 3.4 & $\begin{array}{l}\text { MOTN; } \\
23.202^{\circ} \mathrm{N} \\
121.018^{\circ} \mathrm{E}\end{array}$ & 1.2 & -1.5 & 3.1 & A & 1,430 & $\begin{array}{c}\text { 2003/12/10, } \\
\text { Mw } 6.8\end{array}$ \\
\hline $\begin{array}{l}\text { TTN001; 11934401.CVA; } \\
23.318^{\circ} \mathrm{N}, 121.442^{\circ} \mathrm{E}\end{array}$ & a & 3.7 & 2.6 & $\begin{array}{l}\text { PING; } 23.321^{\circ} \mathrm{N}, \\
121.446^{\circ} \mathrm{E}\end{array}$ & 4.0 & 3.1 & 1.2 & A & 525 & $\begin{array}{l}2003 / 12 / 10 \\
\mathrm{Mw} 6.8\end{array}$ \\
\hline $\begin{array}{l}\text { TTN020; T393001.344; } \\
23.127^{\circ} \mathrm{N}, 121.206^{\circ} \mathrm{E}\end{array}$ & 4.7 & $1.3^{\mathrm{b}}$ & $1.0^{\mathrm{b}}$ & $\begin{array}{l}\text { TAPE; } 23.127^{\circ} \mathrm{N} \\
121.222^{\circ} \mathrm{E}\end{array}$ & 6.9 & 2.6 & -0.1 & A & 1,640 & $\begin{array}{c}2003 / 12 / 10 \\
\text { Mw } 6.8\end{array}$ \\
\hline $\begin{array}{l}\text { TTN004; 11234401.CVA; } \\
22.910^{\circ} \mathrm{N}, 121.129^{\circ} \mathrm{E}\end{array}$ & 3.0 & $-0.7^{\mathrm{b}}$ & $-0.6^{\mathrm{b}}$ & $\begin{array}{l}\text { LONT; } 22.908^{\circ} \mathrm{N}, \\
121.122^{\circ} \mathrm{E}\end{array}$ & 5.1 & -1.0 & -0.4 & A & 760 & $\begin{array}{l}2003 / 12 / 10 \\
\text { Mw } 6.8\end{array}$ \\
\hline $\begin{array}{l}\text { TCU052; T030001.263; } \\
24.198^{\circ} \mathrm{N}, 120.739^{\circ} \mathrm{E}\end{array}$ & 350.5 & 687.9 & -357.7 & $\begin{array}{l}\mathrm{M} 324 ; 24.222^{\circ} \mathrm{N} \\
120.735^{\circ} \mathrm{E}\end{array}$ & 397.2 & 845.1 & -342.3 & $\mathrm{~B}$ & 2,700 & $\begin{array}{l}\text { 1999/09/20, Mw } \\
7.6 \text { Hanging wall }\end{array}$ \\
\hline $\begin{array}{l}\text { TCU074; T202001.263; } \\
23.962^{\circ} \mathrm{N}, 120.962^{\circ} \mathrm{E}\end{array}$ & -66.4 & 137.1 & -193.8 & $\begin{array}{l}\mathrm{HTZS} ; 23.976^{\circ} \mathrm{N} \\
120.974^{\circ} \mathrm{E}\end{array}$ & -60.3 & 128.4 & -187.7 & $\mathrm{~B}$ & 1,950 & $\begin{array}{l}\text { 1999/09/20, Mw } \\
7.6 \text { Hanging wall }\end{array}$ \\
\hline $\begin{array}{l}\text { TCU078; T020001.263; } \\
23.812^{\circ} \mathrm{N}, 120.846^{\circ} \mathrm{E}\end{array}$ & -21.9 & 72.9 & -121.2 & $\begin{array}{l}\mathrm{M} 408 ; 23.779^{\circ} \mathrm{N} \\
120.841^{\circ} \mathrm{E}\end{array}$ & -16.3 & 83.2 & -137.2 & $\mathrm{~B}$ & 3,810 & $\begin{array}{l}\text { 1999/09/20, Mw } \\
7.6 \text { Hanging wall }\end{array}$ \\
\hline $\begin{array}{l}\text { TCU079; T121001.263; } \\
23.839^{\circ} \mathrm{N}, 120.894^{\circ} \mathrm{E}\end{array}$ & -27.8 & 101.6 & -71.9 & $\begin{array}{l}\text { M509; } 23.816^{\circ} \mathrm{N} \\
120.890^{\circ} \mathrm{E}\end{array}$ & -31.0 & 75.5 & -151.9 & $\mathrm{~B}$ & 2,730 & $\begin{array}{l}\text { 1999/09/20, Mw } \\
7.6 \text { Hanging wall }\end{array}$ \\
\hline $\begin{array}{l}\text { TCU137; } 26726300 . I D S ; \\
24.185^{\circ} \mathrm{N}, 120.922^{\circ} \mathrm{E}\end{array}$ & 207.4 & 216.3 & -247.8 & $\begin{array}{l}\mathrm{G} 099 ; 24.173^{\circ} \mathrm{N} \\
120.887^{\circ} \mathrm{E}\end{array}$ & 155.8 & 301.3 & -259.9 & B & 3,810 & $\begin{array}{l}\text { 1999/09/20, Mw } \\
7.6 \text { Hanging wall }\end{array}$ \\
\hline $\begin{array}{l}\text { TCU102; T062001.263; } \\
24.249^{\circ} \mathrm{N}, 120.721^{\circ} \mathrm{E}\end{array}$ & -17.7 & -68.0 & 87.5 & $\begin{array}{l}\mathrm{G} 103 ; 24.262^{\circ} \mathrm{N}, \\
120.710^{\circ} \mathrm{E}\end{array}$ & -10.0 & -59.2 & 66.3 & B & 1,730 & $\begin{array}{l}\text { 1999/09/20, Mw } \\
\text { 7.6 Foot wall }\end{array}$ \\
\hline $\begin{array}{l}\text { TCU060; T240001.263; } \\
24.225^{\circ} \mathrm{N}, 120.644^{\circ} \mathrm{E}\end{array}$ & $-2.5^{\mathrm{b}}$ & $-53.3^{b}$ & 62.2 & $\begin{array}{l}\text { AF } 26 ; 24.223^{\circ} \mathrm{N}, \\
120.643^{\circ} \mathrm{E}\end{array}$ & -6.7 & -38.3 & 55.8 & B & 232 & $\begin{array}{c}\text { 1999/09/20, Mw } \\
7.6 \text { Foot wall }\end{array}$ \\
\hline $\begin{array}{c}\text { TCU054; T111001.263; } \\
24.161^{\circ} \mathrm{N}, 120.675^{\circ} \mathrm{E}\end{array}$ & $-2.8^{\mathrm{b}}$ & -61.5 & $57.5^{\mathrm{c}}$ & $\begin{array}{l}\mathrm{M} 805 ; 24.173^{\circ} \mathrm{N}, \\
120.672^{\circ} \mathrm{E}\end{array}$ & -11.5 & -47.4 & 79.8 & B & 1,230 & $\begin{array}{c}\text { 1999/09/20, Mw } \\
7.6 \text { Foot wall }\end{array}$ \\
\hline $\begin{array}{l}\text { TCU056; T024003.263; } \\
24.159^{\circ} \mathrm{N}, 120.624^{\circ} \mathrm{E}\end{array}$ & $-0.2^{\mathrm{b}}$ & $-61.6^{\mathrm{b}}$ & 46.2 & $\begin{array}{l}\mathrm{AF} 17 ; 24.158^{\circ} \mathrm{N} \\
120.624^{\circ} \mathrm{E}\end{array}$ & -7.4 & -32.1 & 59.1 & B & 96 & $\begin{array}{c}\text { 1999/09/20, Mw } \\
7.6 \text { Foot wall }\end{array}$ \\
\hline $\begin{array}{c}\text { TCU120; T161001.263; } \\
23.980^{\circ} \mathrm{N}, 120.613^{\circ} \mathrm{E}\end{array}$ & $-1.9^{b}$ & $-25.8^{\mathrm{b}}$ & 70.8 & $\begin{array}{l}\mathrm{M} 365 ; 23.968^{\circ} \mathrm{N}, \\
120.619^{\circ} \mathrm{E}\end{array}$ & -15.9 & -21.0 & 70.0 & B & 860 & $\begin{array}{c}\text { 1999/09/20, Mw } \\
7.6 \text { Foot wall }\end{array}$ \\
\hline $\begin{array}{l}\text { TCU076; T091001.263; } \\
23.908^{\circ} \mathrm{N}, 120.676^{\circ} \mathrm{E}\end{array}$ & $-6.5^{\mathrm{b}}$ & -28.0 & 87.3 & $\begin{array}{l}\text { AF } 11 ; 23.896^{\circ} \mathrm{N}, \\
120.676^{\circ} \mathrm{E}\end{array}$ & -17.7 & -32.1 & 88.2 & B & 1,350 & $\begin{array}{c}\text { 1999/09/20, Mw } \\
7.6 \text { Foot wall }\end{array}$ \\
\hline
\end{tabular}

Data source: 2003 Mw6.8 Chengkung earthquake (A) by Chen et al. (2006); 1999 Chi-Chi earthquake (B) by Yu et al. (2001)

${ }^{\text {a }}$ Record of PGA less than $60 \mathrm{~cm} / \mathrm{s}^{2}$

${ }^{\mathrm{b}}$ Permanent displacement less than three standard deviation values

${ }^{\mathrm{c}}$ No correction 
Fig. 6 Top: Observed acceleration for the east-west component at station TCU052 from the 1999 ChiChi, Mw 7.6 earthquake. Middle: Velocities integrated from uncorrected (red) and corrected (black) accelerations. Bottom: Displacements for the uncorrected (red) and corrected (black) cases. After baseline corrections and double integration, $357.7 \mathrm{~cm}$ of permanent westward displacement was obtained. The nearest GPS station, at a distance of about $2.7 \mathrm{~km}$, observed a westward displacement of $342.3 \mathrm{~cm}$. Vertical lines marked by $\mathrm{T} 1, \mathrm{~T} 2$, and $\mathrm{T} 3$ indicate the correction time points. The thick red line plotted in the velocity record shows the correction baseline
TCU052 Raw data, Filename=T030001.263, E-W Component

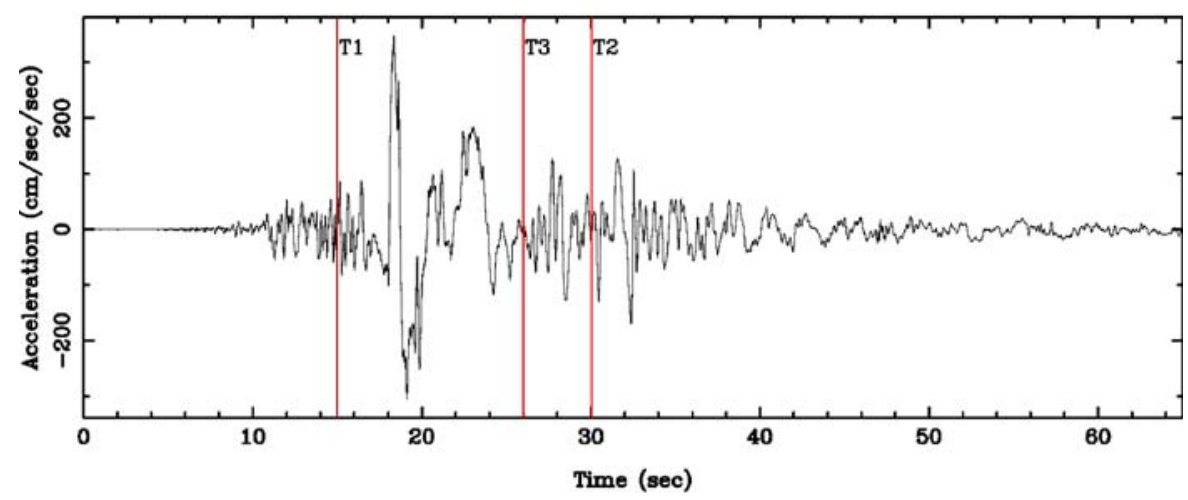

TCU052 Corrected and Raw Data, Filename=T030001.263, E-W Component

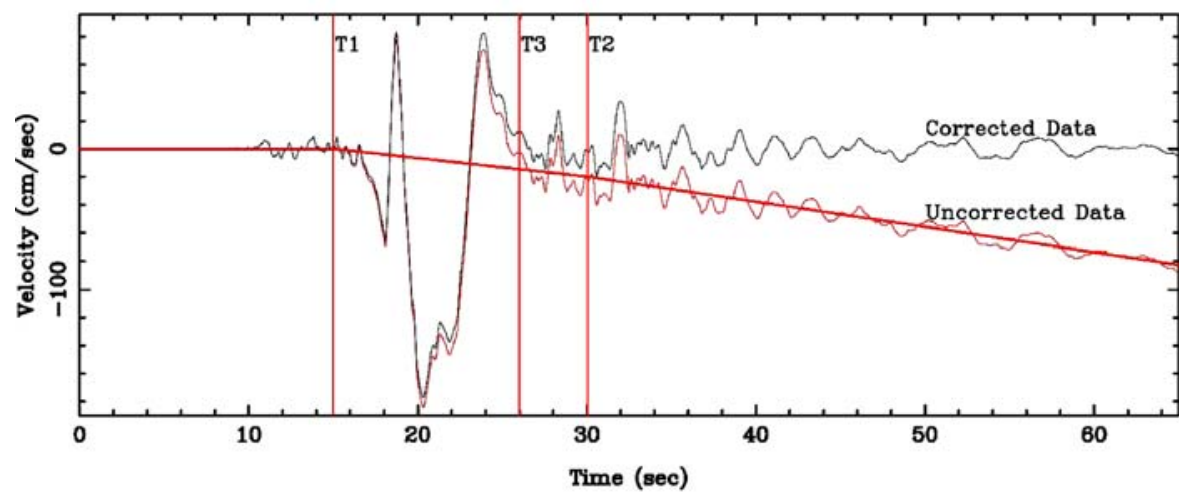

TCU052 Corrected and Raw Data, Filename=T030001.263, E-W Component

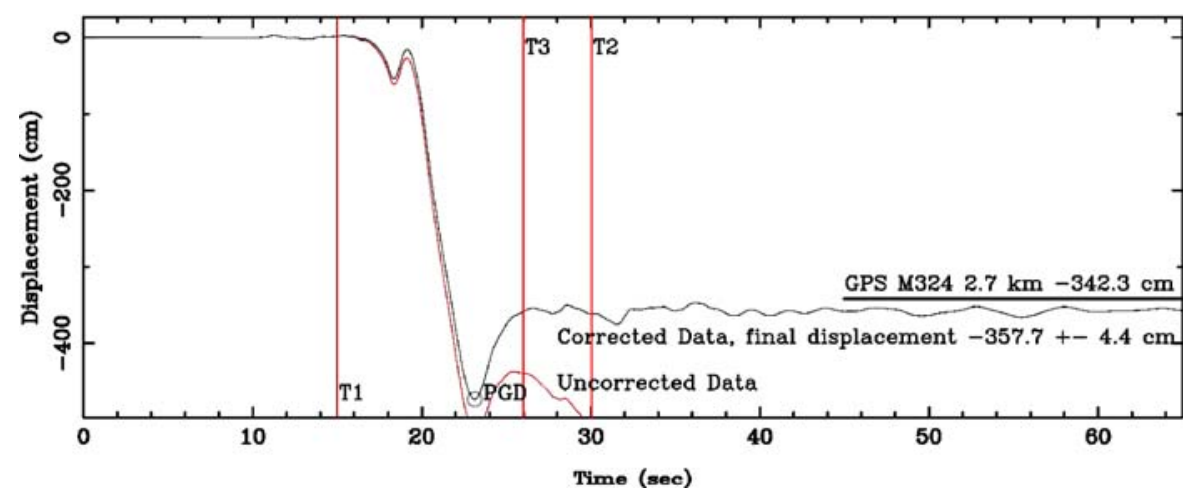

station and GPS station is less than $4 \mathrm{~km}$ for the Chi-Chi earthquake in the hanging wall region and less than $2 \mathrm{~km}$ elsewhere.

Figure 2 displays the raw and corrected data of the east-west component of station TTN014 from the 2003/12/10 Mw=6.8 Chengkung earthquake. After applying our baseline correction method and integrating twice, a permanent eastward displacement of $9.4 \mathrm{~cm}$ was recovered. An almost co-site GPS station observed a 9.3-cm eastward displacement. Vertical lines marked by T1, T2, and T3 in Fig. 2 indicate the correction time points. The thick red line plotted in the velocity history shows the correction baseline. The GPS and strong-motion stations are both operated by the CWB in continuous mode. The GPS measurement did not show any postseismic deformation.

In our method, the time point for selecting $\mathrm{T} 1$ is clear. However, a problem exists for selecting T3 due 


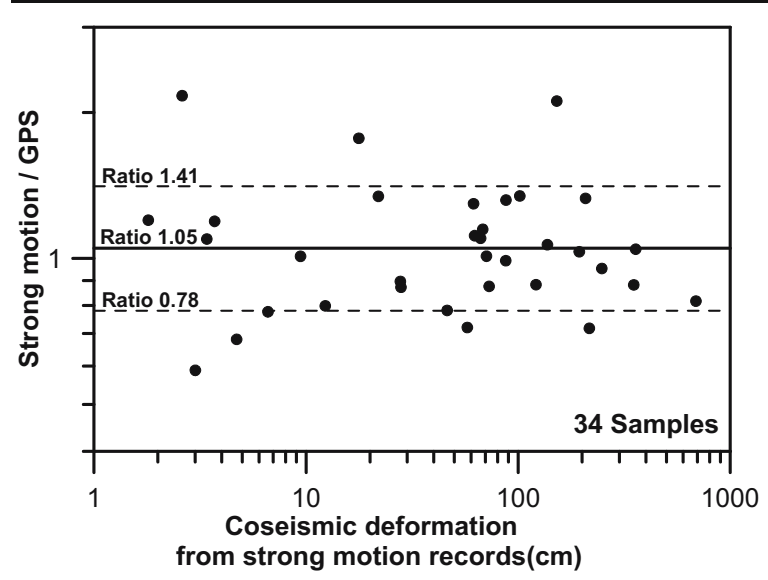

Fig. 7 Ratio of the permanent displacements determined from strong-motion data and from GPS plotted against the displacement determined from the strong-motion data. Solid line shows the mean value and dashed lines show the one standard deviation limits

to the fact that "overshooting" can occur in the corrected displacement history. We suggest that T3 should be chosen at the point where the overshooting has ended and the ground has returned to the permanent displacement position. Figure 6 shows a typical case for selecting T3. The strong-motion record is the east-west component at station TCU052 from the 1999 Chi-Chi, Mw=7.6 earthquake. After baseline correction and double integration, a permanent westward displacement of $357.7 \mathrm{~cm}$ was obtained. It is in good agreement to the measurement of a displacement of $342.3 \mathrm{~cm}$ at the nearest GPS station about $2.7 \mathrm{~km}$ away.

Table 1 lists the permanent displacement results for 16 strong-motion records analyzed in this study and the nearest GPS measurements from Yu et al. (2001) and Chen et al. (2006). A total of 34 components of coseismic displacements were obtained. We did not analyze the records for peak ground acceleration (PGA) less than $60 \mathrm{~cm} / \mathrm{s}^{2}$ because of poor signal-tonoise ratios. We also neglected values of permanent displacements that are less than three standard deviation values.

Figure 7 shows 34 samples of the ratios of coseismic displacements determined from strongmotion data and from GPS observations. The average ratio is about 1.05 with most samples located in the range from 0.78 to 1.41 for one standard deviation limits. Therefore, our results indicate that coseismic displacements from a few centimeters to meters can be determined from the strong-motion records.
Generally, the difference between coseismic displacements determined from strong-motion data and from GPS observations is larger than the error in the results of shake-table tests. We suggest that this is mostly due to source effects. Coseismic displacements determined from strong-motion data contain earthquake source effects. Larger earthquakes have stronger low-frequency signals and more complex source-time functions. However, shake-table "step" tests have well-known sources and more high-frequency signals. The displacements are easier to be recovered and the recovery precision is higher than using earthquake records.

In this study, we have compared the coseismic displacements determined from strong-motion data with those from GPS observations. It provides a firstorder estimation of the upper and lower bounds using our method because most of the GPS and strongmotion stations listed in Table 1 are not located at the same site.

\section{Further examination}

We also applied our method to all of the horizontal strong-motion records from the Chi-Chi earthquake

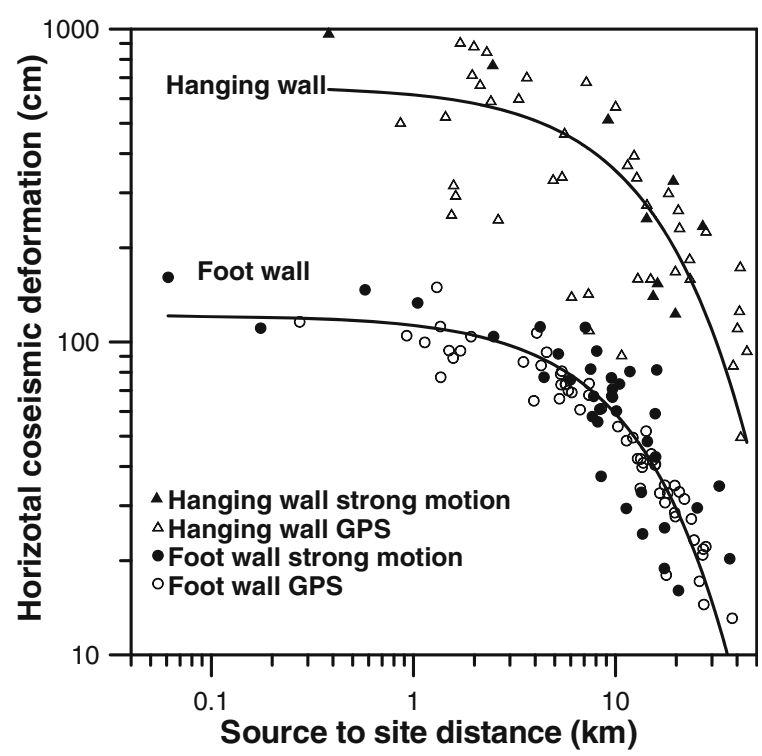

Fig. 8 (a) Horizontal coseismic deformation from GPS and strong motion data versus distance for Chi-Chi earthquake. Triangles and circles show measurements from hanging wall and foot wall, respectively. The two curves show the leastsquares fit results 
Fig. 9 (a) Map showing the coseismic ground slips (blue vectors) determined by strong-motion records and GPS slips (red arrows) from Yu et al. (2001) for both the horizontal and the vertical components of the 1999, Chi-Chi earthquake.

(b) Map showing the coseismic ground slips (blue vectors) determined by strong-motion records and GPS slips (red arrows) from Chen et al. (2006) for both the horizontal and the vertical components of the Chengkung earthquake

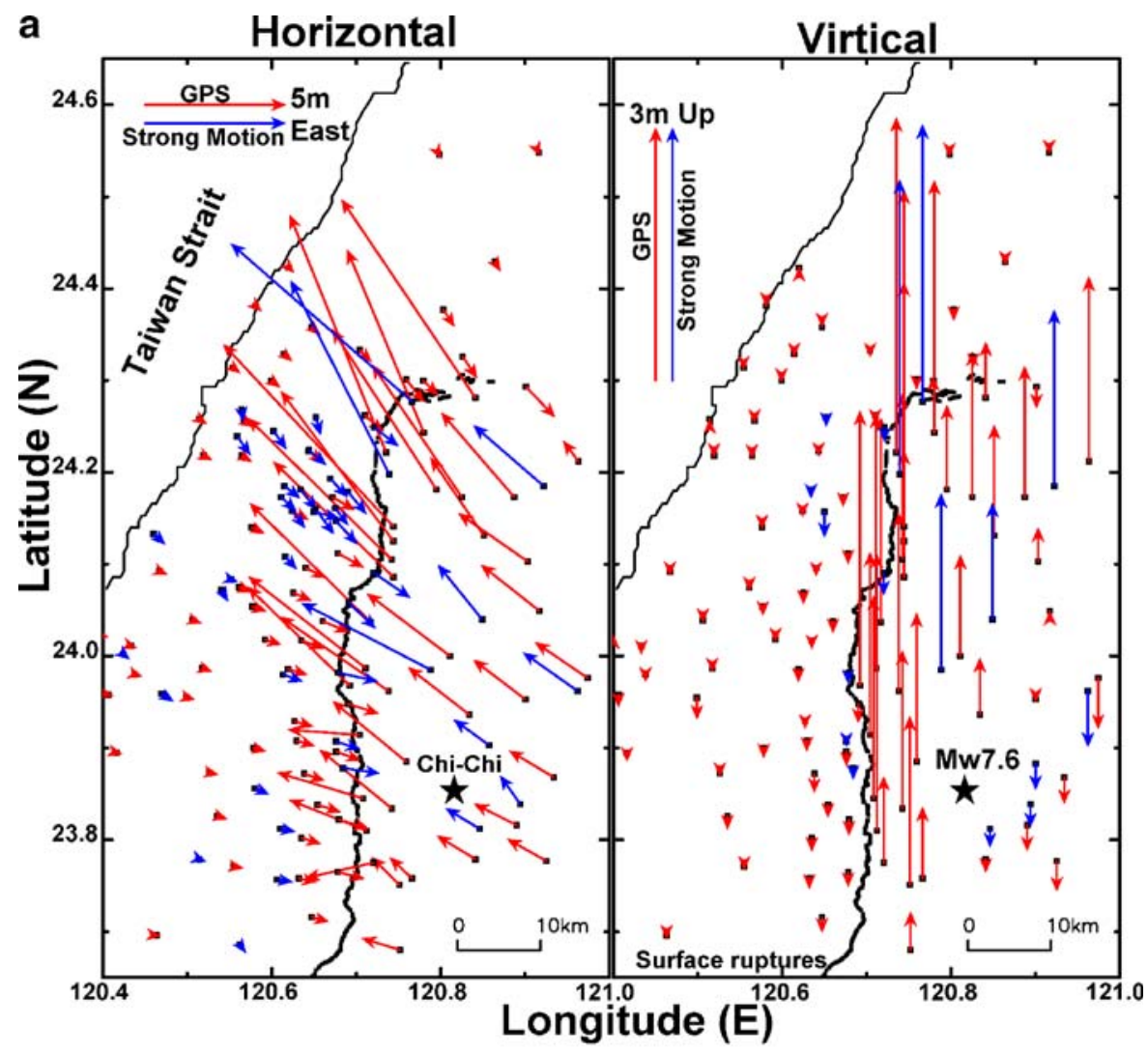

b

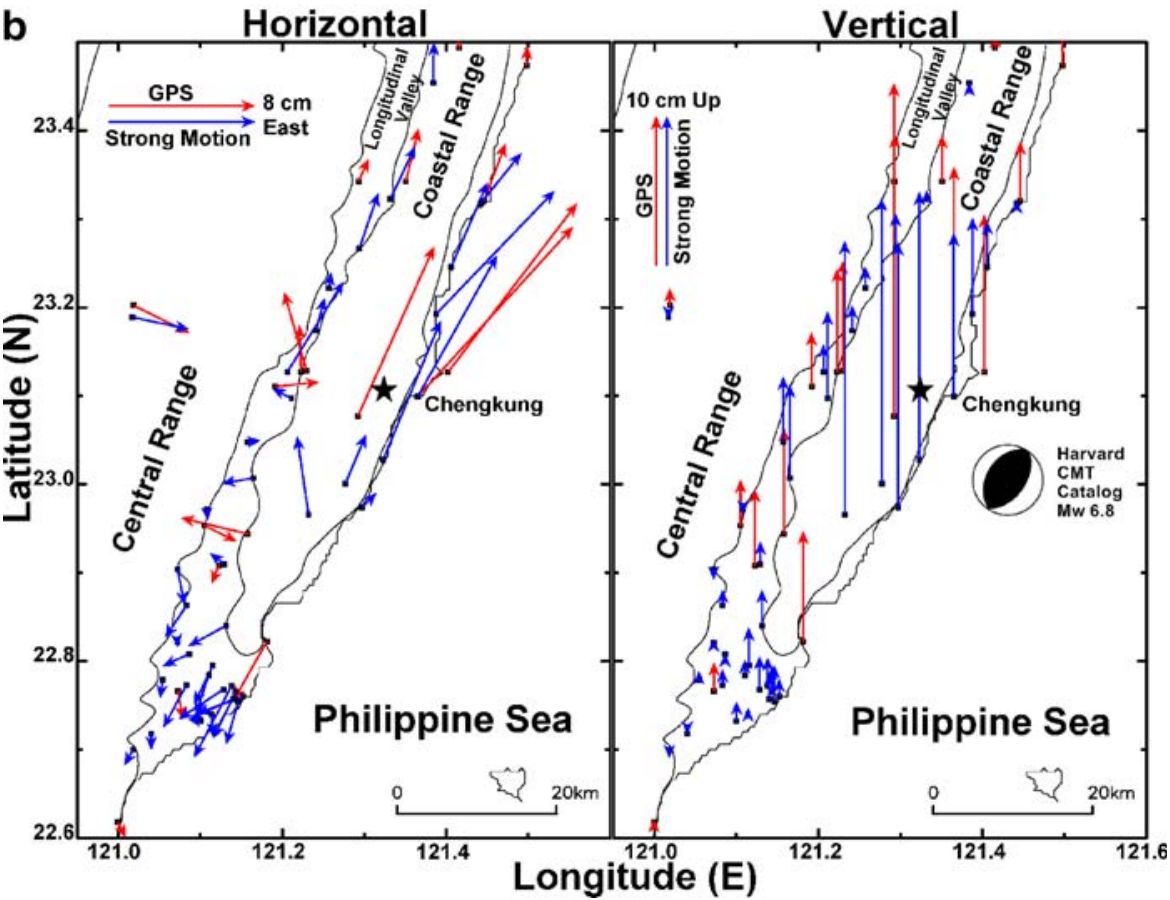


recorded in the near source region. For comparison, we plot horizontal coseismic deformations from GPS and strong-motion data versus the distances $(R)$ from the rupture surface to the sites. Results are shown in Fig. 8, and the two results agree favorably with each other. The Chi-Chi earthquake is a typical thrust event (Chang et al. 2000). The horizontal coseismic deformation characteristics are quite different between hanging and footwalls. Using the attenuation formula of Wu et al. (2001) and data from GPS (Yu et al. 2001) and strong-motion records, we obtained two least-squares fit curves for the coseismic deformation (D) of the Chi-Chi earthquake:

for hanging wall

$\log (\mathrm{D})=2.279+0.300 \mathrm{M}_{\mathrm{W}}-0.0198 \mathrm{R}-$

$\log \left(\mathrm{R}+0.00871 \times 10^{0.5 \mathrm{Mw}}\right)$

for foot wall

$$
\begin{aligned}
\log (\mathrm{D})= & 1.912+0.252 \mathrm{M}_{\mathrm{w}}-0.0239 \mathrm{R} \\
& -\log \left(\mathrm{R}+0.00871 \times 10^{0.5 \mathrm{Mw}}\right) .
\end{aligned}
$$

Figure 8 also shows these two least-squares fit curves. Although it may not provide a good constraint for studying the attenuation relationship since records from only one event are used, the curves give a good reference for the examination of coseismic deformation using strong-motion data.

We further applied our method to all of the strongmotion records from the Chi-Chi and Chengkung earthquakes recorded in the near source region. Figure $9 \mathrm{a}$ and $\mathrm{b}$ shows the ground slips from strongmotion records, which are very consistent with the GPS slips (Chen et al. 2006; Yu et al. 2001) for both Chi-Chi and Chengkung earthquakes, respectively. This further validates our method. The Chengkung earthquake produced a large amount of afterslips (Lee et al. 2006). Thus, in Fig. 9b, only continuous GPS measurements were used.

\section{Conclusions}

We have proposed a new approach to baseline corrections to recover the coseismic displacements from strong-motion records. The sources of the baseline shifts are numerous, as pointed out by Boore et al. (2002) and Boore and Bommer (2005). Tilting of the ground is one of the causes, for example, and at least two baseline correction steps are necessary. For the cases shown in Figs. 2 and 6, we have tried to apply a single baseline correction to determine the displacement. However, the results did not agree with the GPS observations. Certainly, two-step baseline corrections are just an empirical approach before the sources of the baseline shifts are clearly understood and six-component strong-motion records are available (Graizer 1989, 2005; Niggbor 1994; Trifunac and Todorovska 2001).

In this study, we developed the baseline correction method based on the work of Iwan et al. (1985) and Boore (2001). We examined our method using an extensive set of data from shake-table tests of a known displacement on 249 accelerographs. Our baseline correction method recovered about $97 \%$ of the actual displacement from the shake-table data. We then applied this baseline correction method to compute coseismic displacements from the strongmotion data of the Chi-Chi and Chengkung earthquakes. Our results agree favorably with the coseismic displacements determined by the GPS measurements at nearby sites. The ratio of seismic to geodetic displacement varies from 0.78 to 1.41 , with an average ratio of about 1.05. Our baseline correction approach is validated by comparisons for both shake-table tests and for actual earthquakes.

Acknowledgements The authors wish to thank Dr. Willie Lee, Dr. David Boore, and Dr. Li Zhao for providing many thoughtprovoking comments. Wu also wish to thank the two anonymous reviewers who made very constructive and helpful comments, and Yu-Ting Kuo and Li-Wei Cheng for the kind help. This research was supported by the National Science Council of the Republic of China under grant nos. NSC94-2116-M-002-021, NSC95-2625-Z-002-028, and NSC95-2119-M-002-043-MY3.

\section{References}

Bogdanov VE, Graizer VM (1976) The determination of the residual displacement of the ground from the seismogram. Reports of the Academy of Sciences of the USSR 229:59-62

Boore DM (2001) Effect of baseline corrections on displacement and response spectra for several recordings of the 1999 Chi-Chi, Taiwan, earthquake. Bull Seismol Soc Am 91:1199-1211

Boore DM, Bommer JJ (2005) Processing of strong-motion accelerograms: needs, options and consequences. Soil Dyn Earthqu Eng 25:93-115

Boore DM, Stephens CD, Joyner WB (2002) Comments on baseline correction of digital strong-motion data: examples from the 1999 Hector Mine, California, earthquake. Bull Seismol Soc Am 92:1543-1560 
Chang CH, Wu YM, Shin TC, Wang CY (2000) Relocating the 1999 Chi-Chi earthquake, Taiwan. Terr Atmos Oceanic Sci 11:581-590

Chen HY, Yu SB, Kuo LC, Liu CC (2006) Coseismic and postseismic displacement of the 10 December 2003 (Mw 6.5) Chengkung, eastern Taiwan, earthquake. Earth Planet Space 58:5-21

Chiu HC (1997) Stable baseline correction of digital strongmotion data. Bull Seismol Soc Am 87:932-944

Chung JK, Shin TC (1999) Implication of the rupture process from the displacement distribution of strong ground motions recorded during the 21 September 1999 Chi-Chi, Taiwan earthquake. Terr Atmos Oceanic Sci 10:777-786

CWB Instrumentation Committee (1994) A preliminary report on testing accelerographs and accelerometers. Appendix 1, Technical Report No. 7. Seismology Center, Central Weather Bureau, Taipei, Taiwan

Graizer VM (1979) Determination of the true ground displacement by using strong motion records. Izv Earth Phys 25:26-29

Graizer BM (1989) On inertial seismometry. Izv Earth Phys 25:26-29

Graizer VM (2005) Effect of tilt on strong motion data processing. Soil Dyn Earthqu Eng 25:197-204

Iwan WD, Moser MA, Peng CY (1985) Some observations on strong-motion earthquake measurement using a digital accelerograph. Bull Seismol Soc Am 75:1225-1246

Lee WHK, Shin TC, Kuo KW, Chen KC (1999) CWB freefield strong-motion data from the $921 \mathrm{Chi}-\mathrm{Chi}$ earthquake: volume 1 digital acceleration files on CD-ROM. Central Weather Bureau, Taipei, Taiwan

Lee WHK, Shin TC, Kuo KW, Chen KC, Wu CF (2001) CWB free-field strong-motion data from the 21 September ChiChi, Taiwan, earthquake. Bull Seismol Soc Am 91:13701376 (with data files on the attached CD-ROM)
Lee JC, Chu HT, Angelier J, Hu JC, Chen HY, Yu SB (2006) Quantitative analysis of surface coseismic faulting and postseismic creep accompanying the 2003, Mw $=6.5$, Chengkung earthquake in eastern Taiwan. J Geophys Res 111:B02405, doi: http://dx.doi.org/10.1029/2005JB003612

Niggbor RL (1994) Six-degree-of-freedom ground-motion measurement. Bull Seismol Soc Am 84:1665-1669

Shin TC, Tsai YB, Yeh YT, Liu CC, Wu YM (2003) Strongmotion instrumentation programs in Taiwan. In: Lee WHK, Kanamori H, Jennings PC, Kisslinger C (eds) Handbook of earthquake and engineering seismology. Academic, San Diego, pp 1057-1062

Trifunac MD, Todorovska MI (2001) A note on the useable dynamic range of accelerographs recording translation. Soil Dyn Earthqu Eng 21:275-286

Wu YM, Shin TC, Chang CH (2001) Near realtime mapping of peak ground acceleration and peak ground velocity following a strong earthquake. Bull Seismol Soc Am 91:1218-1228

Wu YM, Chen YG, Shin TC, Kuochen H, Hou CS, Hu JC, Chang $\mathrm{CH}$, Wu CF, Teng TL (2006a) Coseismic versus interseismic ground deformations, fault rupture inversion and segmentation revealed by $2003 \mathrm{Mw}$ 6.8 Chengkung earthquake in eastern Taiwan. Geophys Res Lett 33: L02312, doi: http://dx.doi.org/10.1029/2005GL024711

Wu YM, Chen YG, Chang CH, Chung LH, Teng TL, Wu FT, Wu CF (2006b) Seismogenic structure in a tectonic suture zone: with new constraints from 2006 Mw6.1 Taitung earthquake. Geophys Res Lett 33:L22305, doi: http://dx. doi.org/10.1029/2006GL027572

Yu SB, Kuo LC, Hsu YR, Su HH, Liu CC, Hou CS, Lee JF, Lai TC, Liu CC, Liu CL (2001) Preseismic deformation and coseismic displacements associated with the 1999 ChiChi, Taiwan, earthquake. Bull Seismol Soc Am 91:9951012 (with data files on the attached CD-ROM) 